\title{
Disease Burden and Healthcare Costs for T2D Patients With and Without Established Cardiovascular Disease in Sweden: A Retrospective Cohort Study
}

\author{
Lars Bernfort (1) · Magnus Husberg • Ann-Britt Wiréhn • \\ Ulf Rosenqvist · Staffan Gustavsson · Kristina Karlsdotter • \\ Lars-Åke Levin
}

Received: April 20, 2020 / Published online: May 28, 2020

(C) The Author(s) 2020

\begin{abstract}
Introduction: Type 2 diabetes (T2D) is a complex chronic disease with an increasing prevalence worldwide. It is commonly associated with complications, such as cardiovascular disease (CVD). Patients with both T2D and established CVD are exposed to increased risk of further cardiovascular events, which means increased healthcare costs and impairments to quality of life and survival. To determine the added burden of CVD for T2D patients, we have analyzed the consumption and costs of healthcare and mortality in two T2D patient cohorts,
\end{abstract}

Digital Features To view digital features for this article go to https://doi.org/10.6084/m9.figshare.12279929.

L. Bernfort $(\bowtie) \cdot$ M. Husberg · A.-B. Wiréhn · L.- $\AA$. Levin

Department of Health, Medicine and Caring

Sciences, Linköping University, Linköping, Sweden e-mail: lars.bernfort@liu.se

A.-B. Wiréhn

Research and Development Unit, Region

Östergötland, Linköping, Sweden

U. Rosenqvist

Department of Internal Medicine, Motala Hospital,

Motala, Sweden

S. Gustavsson · K. Karlsdotter

Boehringer Ingelheim AB, Stockholm, Sweden with and without established CVD, respectively, during a 5-year follow-up in a Swedish region.

Methods: Patients with T2D on 1 January 2012 were identified using the administrative database of Region Östergötland and the Swedish National Diabetes Register. Established CVD was defined as the presence of a CVD-related healthcare visit in the period 2002-2011. Identified T2D patients were then followed retrospectively for 5 years (2012-2016) and data collected on utilization of healthcare resources, healthcare costs, and survival. Data pertinent to the study were retrieved from regional databases and national registries.

Results: On the index date (1 January 2012) there were 19,731 patients with T2D (prevalence $4.5 \%$ ) in Region Östergötland, of whom 5490 had established CVD. Those patients with established CVD were older, more often men, and had longer diabetes duration and worse kidney function than those without. Compared to T2D patients without CVD, those with CVD had a significantly higher healthcare consumption, experienced higher costs, and had lower survival during the follow-up.

Conclusion: This study confirms that established CVD is common among patients with T2D (approximately 30\%). Established CVD has negative effects on the utilization of healthcare resources, healthcare costs, and mortality. It is therefore very important to improve the treatment strategy of this patient group. 
Keywords: Cardiovascular disease; Disease burden; Healthcare costs; Mortality; Observational study; Register study; Type 2 diabetes

\section{Key Summary Points}

Cardiovascular disease (CVD) has been reported to be common in patients with type 2 diabetes (T2D).

Patients with T2D and concomitant CVD are believed to represent a particularly vulnerable group.

The aim of this study was to calculate the healthcare costs of and to describe mortality in patients with T2D, with and without established cardiovascular disease, respectively, during a 5-year follow-up in a Swedish region.

The results confirm that CVD is common among patients with T2D and that CVD in these patients is associated with both higher healthcare costs and higher mortality.

Patients with T2D and established CVD respresent a vulnerable group for which it is important to improve the treatment strategy.

\section{INTRODUCTION}

Diabetes is a complex chronic disease, and its prevalence is steadily increasing over time [1]. According to recent reports, diabetes affects one in 11 adults, or about 425 million people globally [2]; of these, approximately 90-95\% have type 2 diabetes (T2D) [3]. The prevalence of T2D in Sweden has been reported to be approximately $5 \%$ of the adult population [4], which is a prevalence of about $4 \%$ of the general population. Not only is the prevalence of T2D rising, due in part to an aging world population, lifestyle changes, and the increased prevalence of obesity, T2D is also associated with various complications and an elevated risk for different comorbidities, such as cardiovascular disease (CVD). A recent study reported that the prevalence of CVD in patients with T2D in Sweden is $28.3 \%$ [5].

Although the mortality and the incidence of cardiovascular outcomes among people with diabetes has declined over time [6], while our knowledge of risk factors for disease has improved together with our treatment of them [7], complications associated with T2D and its comorbidities still lead to an increased burden of both disease and healthcare consumption [8], which in turn leads to an impaired quality of life for affected individuals and increased healthcare costs $[1,9-12]$. Altogether, these factors results in T2D being a major and growing challenge to public healthcare services.

In recent years, new medications targeted for the treatment of patients with T2D (dipeptidyl peptidase-4 [DPP-4] inhibitors, glucagon-like peptide-1 [GLP-1] receptor agonists, and sodium-glucose co-transporter-2 [SGLT-2] inhibitors) have been developed which, in addition to controlling blood sugar, also lower the risk of, for example, cardiovascular events or are considered to be safe for use by patients with CVD [13-15]. A growing body of evidence has led the Swedish National Board of Health and Welfare to recommend that SGLT-2-inhibitors or GLP-1-receptor agonists be used in the treatment of patients with T2D and established CVD [4]. Similar recommendations were set forth in a joint statement by the European Society of Cardiology (ESC) and the European Association for the Study of Diabetes (EASD) [16] and in a joint statement by the American Diabetes Association (ADA) and the EASD [17].

Due to the high prevalence of diabetes it is important that decision-makers make informed decisions and well-founded prioritizations. Patients with T2D and established CVD seem to be particularly exposed with respect to burden of disease, and their associated healthcare costs are higher than those of patients with T2D without established CVD [5, 9]. Quantifying healthcare resource utilization and estimating healthcare costs for patients diagnosed with T2D will add to the evidence base supporting decision-making in this patient population. 
Available Swedish studies on the cost incurred by a T2D patient are primarily cross-sectional with a short follow-up [12, 18-21], or they are based on an unselected T2D population [22] and not sufficient to provide an understanding of the utilization of healthcare services by patients with T2D and established CVD over a longer time horizon.

Given this lack of sufficient data and the high prevalence of T2D, we have analyzed healthcare data on a geographically defined cohort of all patients with T2D and established CVD, with respect to long-term healthcare consumption and mortality. The patient population in this study included all patients with T2D in Östergötland, a region in south-east Sweden which has approximately 460,000 permanent residents, representing $4.5 \%$ of the Swedish population. The healthcare system in Sweden is primarily publicly financed and administered and is available to all residents.

The aim of this study was to describe the patient population with T2D and established CVD and to compare these patients with T2D patients without established CVD, with respect to burden of disease, healthcare consumption, and healthcare costs.

\section{METHODS}

\section{Study Design}

This study was a population-based retrospective observational study in which historical data on healthcare consumption and mortality among T2D patients with and without established CVD were collected and analyzed for a 5-year period between 2012 and 2016. As possible, we applied the inclusion and exclusion criteria of the EMPA REG Outcomes Study [23], in which study patients with T2D and established CVD were administered empagliflozin, to define patients with established CVD.

The study was approved by the Regional Ethics Research Committee in Östergötland, Sweden (Dnr: 2017/535-31) and was performed in accordance with the Helsinki Declaration of 1964, and its later amendments.

\section{Data Sources}

The primary data sources were patient data extracted from national health registers, including the Pharmaceutical Registry and the Cause of Death Registry, the National Diabetes Registry (NDR), and the Östergötland regional administrative registry (Healthcare Data Warehouse [VDL]).

The Pharmaceutical Registry contains all prescription medicines collected in pharmacies [24]. This register also contains data on extracted items other than medicinal products-if they are part of the national benefit system. There are just over 100 million entries per year in this registry. In this study, the Anatomical Therapeutic Chemical Classification System (ATC) code, date, and withdrawal costs between 1 January 2012 and 31 December 2016 were extracted for the study population.

The Cause of Death Registry covers all deaths that occur in Sweden [25]. It also includes the deaths of persons not registered in Sweden at the time of death. In this study, the register was used solely to extract the date of death of patients in the study cohort.

The NDR [26] was founded in 1996 as a tool for local quality control and to better align with national treatment targets. The NDR contains data on the type of diabetes (type 1 diabetes [T1D] or T2D), demographic factors, diabetes duration, treatments, risk factors, and diabetes complications. The register's coverage rate is estimated to be $94 \%$ [26]. Registration immediately before 1 January 2012 was used in this study to extract data on patient status on 1 January 2012 with respect to weight, height, body mass index (BMI), diabetes duration, age at onset, year of first glycated hemoglobin measurement, low-density lipoprotein, blood pressure, glomerular filtration rate (GFR), albuminuria, and type of diabetes.

The Östergötland VDL contains information on patients' characteristics, visits to healthcare providers, and hospital stays (including number of inpatient days). For each care episode registered in the VDL, there is information on diagnoses, inpatient care, outpatient care, and primary care. The VDL system is linked to a cost-per-patient database (KPP) in which one 
cost entity is linked to each contact. The VDL registry has almost complete coverage (close to $100 \%$ ) as all contacts provided by the Swedish publicly financed healthcare system are registered. The volume of healthcare visits to private providers is available, but not their prices. For this study, these prices were taken to be the average of publicly provided visits.

All inhabitants in Sweden have unique IDnumbers that enable data from the different registers to be linked. In this study, the actual linking of the data was performed by the National Board of Health and Welfare, which also held the identification key. All diagnoses were coded according to the International Classification of Diseases, tenth revision (ICD10).

\section{Study Population}

The study population was defined by first identifying all patients in the region of Östergötland with at least one diabetes ICD-10 code between 1 January 2009 and 31 December 2011 in the VDL. Thereafter, the Östergötland VDL and the NDR were searched to exclude patients with T1D, leaving only T2D patients in the study population. These T2D patients were then screened and the exclusion criteria used in the EMPA REG Outcome study [23] applied: age < 18 years; $\mathrm{BMI}>45$; reduced kidney function (GFR $<30 \mathrm{ml} / \mathrm{min}$ ); and recent ( 2 months prior to study start) stroke, transient ischemic attack (TIA) or acute coronary syndrome (ACS).

Those T2D patients who met the inclusion criteria were subsequently divided into two cohorts, those with established CVD (T2D-CVD cohort) and those without established CVD (T2D-others cohort). Established CVD was defined based on the inclusion criteria in the EMPA REG Outcome study and translated into diagnoses and measures registered in inpatient care during a 10 -year period prior to 2012 , as shown in Table 1 . The most common reasons for inclusion in the T2D-CVD cohort were myocardial infarction (MI) and stroke. A flow chart of study enrollment and allocation to the two patient cohorts is shown in Fig. 1.
For the analysis of costs during the 5-year study period (2012-2016), healthcare consumption was retrieved from the VDL and drug consumption from the national Pharmaceutical Registry. Date of death was retrieved from the Cause of Death Registry.

\section{Statistics}

This was a descriptive analysis of two patient cohorts: T2D-CVD and T2D-others. The use of healthcare resources and associated costs, as well as mortality, were described for the two cohorts. Proportions were reported as percentages, and Chi-square tests were used to test the significance of differences between groups. Means were used as measures of central tendencies, and the standard deviation was used as a measure of distribution. Group mean differences were tested with $t$ tests. A significance level of $p=0.05$ was used throughout. Survival in the different groups was shown using Kaplan-Meier curves. Group differences in survival were also tested with Cox regression due to differences in age and sex distribution.

\section{RESULTS}

The study population consisted of 18,586 patients with T2D, of whom 5490 (30\%) also had established CVD; these latter 5490 patients constituted the T2D-CVD cohort.

The baseline characteristics of the primary study population, i.e., the T2D-CVD cohort, are presented in Table 2 and compared with those of the T2D-others cohort. Compared with the T2D other cohort, there were more men in the T2D-CVD cohort, and the patients were older (average 7 years), had longer diabetes duration, had worse kidney function, more often had macro- or microalbuminuria, and were more frequently treated with insulin (35 vs. $25 \%$ of patients). Fewer patients in the T2D-CVD cohort compared to the T2D-others cohort received glucose-lowering drugs (GLDs) other than insulin (38 vs. $48 \%$ ). In both groups, 38\% of patients received no glucose-lowering medication. 
Table 1 Distribution of cardiovascular events defining the cohort of patients with type 2 diabetes and established cardiovascular disease

\begin{tabular}{lc}
\hline Cardiovascular event & T2D-CVD cohort $^{\mathbf{a}}(\boldsymbol{n}=\mathbf{5 4 9 0 )}(\%)$ \\
\hline Any cardiovascular event & 100.0 \\
Coronary artery disease (CAD) & 77.4 \\
Myocardial infarction (MI) ${ }^{\mathrm{b}}$ & 26.1 \\
Stroke & 24.8 \\
Percutaneous coronary intervention & 19.5 \\
Peripheral artery disease & 14.5 \\
Coronary artery bypass graft & 9.3 \\
Amputation & 1.8 \\
Carotid or femoral angioplasty & 1.3 \\
Cardiac arrest & 0.9 \\
\hline a Cohort of patients with type 2 diabetes (T2D) and established cardiovascular disease (CVD) \\
b Percentage of those with CAD who had MI
\end{tabular}

\section{Inpatient Care Consumption}

Comparison of the T2D-CVD and T2D-others cohort showed that inpatient care was received by $67.7 \%$ of patients in the T2D-CVD cohort and by $44 \%$ of those in the T2D-others cohort. As would be expected, significantly more patients in the T2D-CVD cohort received care for CVD (47 vs. 21\%). Larger proportions of the T2D-CVD cohort also received care for microvascular disease (2.8 vs. $1 \%)$, diabetes ( 23.6 vs. $15.4 \%)$, kidney disease (3.8 vs. $1.4 \%)$, lower limb amputations (1.5 vs. $0.4 \%)$, and other causes (46.5 vs. $30.2 \%)$. The average number of healthcare visits in the respective cohorts are summarized in Table 3.

\section{Costs}

Costs attributable to different types of healthcare servuces and medications for T2D patients with and without established CVD are summarized in Table 4.

Total costs per patient, including all healthcare and medications, summed up to SEK 222,416 in the T2D-CVD cohort and SEK 132,456 in the T2D-others cohort. Of these costs, SEK 76,508 and 29,449, respectively, were attributable to CVD. The major cost differences between patients with and without established CVD consisted of costs for healthcare visits, especially inpatient care. Medications made up $21 \%$ of total costs in the T2D-CVD cohort and $31 \%$ of total costs in the T2D-others cohort. Less than half of the medication costs were directly related to diabetes or CVD. Patients in the T2DCVD cohort had higher costs for insulin and lower costs for other GLDs compared to those in the T2D-others cohort. Total cost differences in terms of medications were relatively modest, with patients in the T2D-CVD cohort on average consuming medications worth about SEK 5000 more during the 5-year follow-up.

\section{Mortality}

Death from any causes during the 5 years differed between T2D patients with and without established CVD, as shown in Fig. 2. All patients were followed for 1826 days (5 years).

Patients with T2D and established CVD clearly had a higher risk of death from any cause within 5 years compared with T2D patients without established CVD (34 vs. 15\%, or a 140\% 


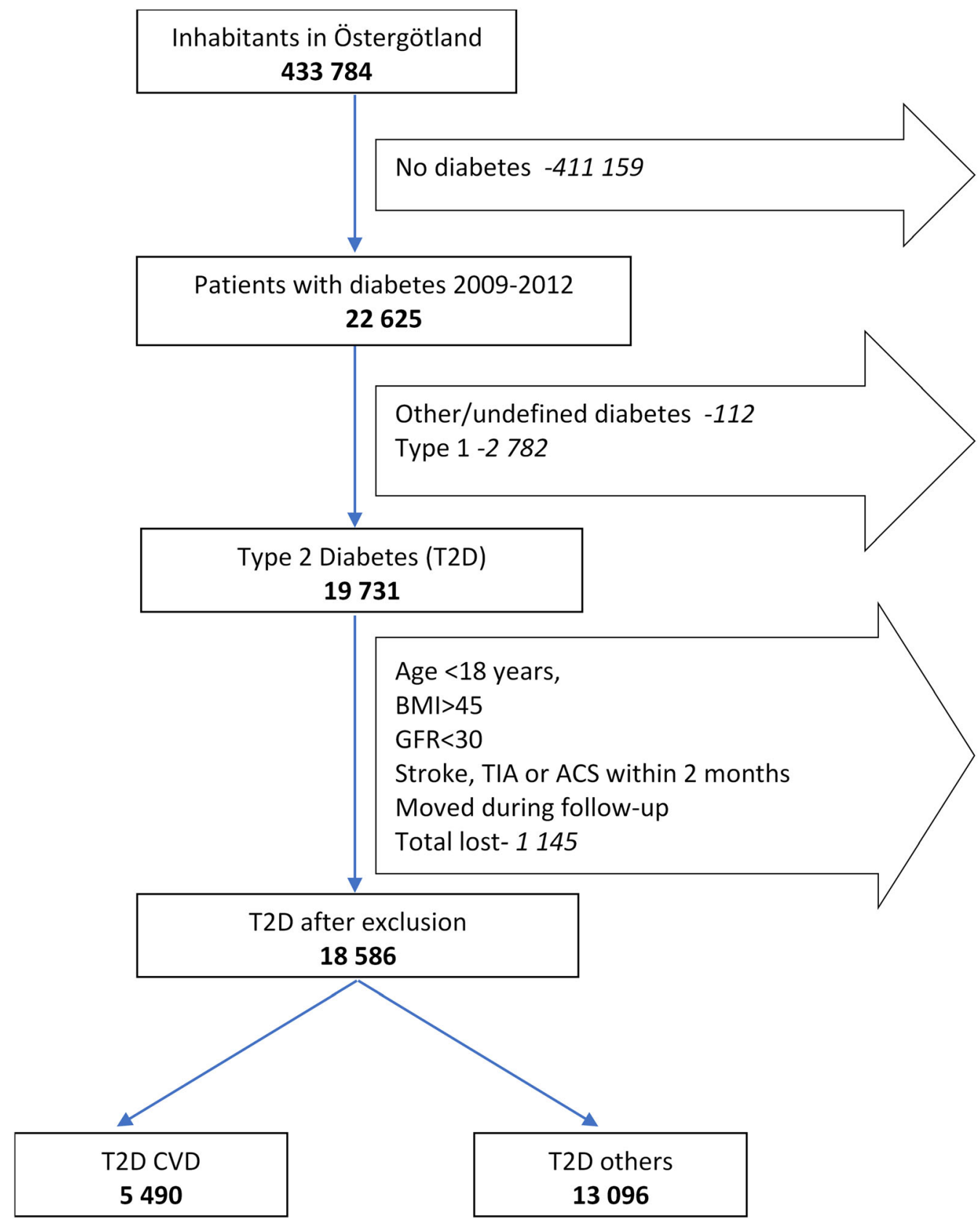

Fig. 1 Flow chart of study enrollment and allocation to two patient cohort groups (T2D-CVD patients with T2D and established cardiovascular disease [CDV]; T2D-others patients with T2D without established CVD). ACS Acute

higher risk). Cox-regression showed that adjusted for age and gender, the T2D-CVD cohort had a death hazard ratio of 1.69 (95\% confidence interval 1.58-1.80) compared to the T2Dothers cohort, indicating that the presence of coronary syndrome, $B M I$ body mass index, GFR glomerular filtration rate, $T 2 D$ type 2 diabetes, $T I A$ transient ischemic attack

CVD in T2D patients is associated with a $69 \%$ excess mortality risk. On average, patients in the T2D-CVD cohort lived 198 days less during the follow-up than those in the T2D-others cohort $(-12 \%)$. 
Table 2 Patient characteristics at baseline (1 January 2012) and comparisions of the T2D-CVD and T2D-others cohorts, and of all T2D patients enrolled in study

\begin{tabular}{|c|c|c|c|c|c|}
\hline Patient characteristics at baseline & $N^{a}$ & $\begin{array}{l}\text { T2D-CVD } \\
\text { cohort }\end{array}$ & $\begin{array}{l}\text { T2D-others } \\
\text { cohort }\end{array}$ & $p$ & $\begin{array}{l}\text { All T2D } \\
\text { patients }^{c}\end{array}$ \\
\hline Number of patients & 18,586 & 5490 & 13,096 & & 18,586 \\
\hline Age, years (average, SD) & 18,586 & 73.5 & 66.3 & 0.000 & 68.4 \\
\hline Sex (\% male) & 18,586 & $3191(58 \%)$ & $6945(53 \%)$ & 0.000 & $10,136(55 \%)$ \\
\hline \multicolumn{6}{|l|}{ Values at last visit before $2012^{\mathrm{d}}$} \\
\hline BMI & 13,605 & 29.5 & 29.8 & 0.001 & 29.7 \\
\hline Height $(\mathrm{cm})$ & 16,169 & 169.5 & 170.2 & 0.000 & 170.0 \\
\hline Weight $(\mathrm{kg})$ & 13,870 & 85.1 & 86.7 & 0.000 & 86.3 \\
\hline Diabetes duration (years) & 16,727 & & & & \\
\hline$\leq 5$ & & $1178(24 \%)$ & $4039(34 \%)$ & 0.000 & $5217(31 \%)$ \\
\hline $5-10$ & & $1226(25 \%)$ & $3155(27 \%)$ & 0.000 & $4381(26 \%)$ \\
\hline$>10$ & & $2522(51 \%)$ & $4607(39 \%)$ & 0.000 & $7129(43 \%)$ \\
\hline Year of inclusion in database & 16,727 & 2000 & 2002 & 0.000 & 2002 \\
\hline Age (years) at inclusion in database & 16,727 & 62 & 58 & 0.000 & 59 \\
\hline $\mathrm{HbAlc}(\mathrm{mmol} / \mathrm{mol})$ & 15,759 & 54 & 53 & 0.000 & 53 \\
\hline Cumulative LDL-cholesterol (mmol/l) & 4168 & 2.3 & 2.6 & 0.000 & 2.5 \\
\hline Systolic blood pressure $(\mathrm{mmHg})$ & 14,996 & 133 & 134 & 0.000 & 134 \\
\hline Diastolic blood pressure $(\mathrm{mmHg})$ & 14,955 & 72 & 76 & 0.000 & 75 \\
\hline Glomerular filtration rate $(\mathrm{ml} / \mathrm{min})$ & 11,615 & & & & \\
\hline$\geq 90$ & & $549(16 \%)$ & $2110(26 \%)$ & 0.000 & $2659(23 \%)$ \\
\hline $60<90$ & & $1625(47 \%)$ & $4420(54 \%)$ & 0.000 & $6045(52 \%)$ \\
\hline$<60$ & & $1263(37 \%)$ & $1648(20 \%)$ & 0.000 & $2911(25 \%)$ \\
\hline Albuminuria (category) & 9984 & & & & \\
\hline 0 (no) & & $1843(65 \%)$ & $5569(78 \%)$ & 0.000 & $7412(74 \%)$ \\
\hline 1 (normal) & & $92(3 \%)$ & $191(3 \%)$ & 0.000 & $283(3 \%)$ \\
\hline 2 (microalbuminuri) & & $570(20 \%)$ & $1031(14 \%)$ & 0.000 & $1601(16 \%)$ \\
\hline 3 (macroalbuminuri) & & $316(11 \%)$ & $372(5 \%)$ & 0.000 & $688(7 \%)$ \\
\hline \multicolumn{6}{|c|}{ Drugs within 3 months after 1 January $2012^{\mathrm{e}}$} \\
\hline Insulin (A10A) & 18,586 & $1905(35 \%)$ & $3241(25 \%)$ & 0.000 & $5146(28 \%)$ \\
\hline Biguanide derivate (A10BA) & 18,586 & $1713(31 \%)$ & $5429(41 \%)$ & 0.000 & $7142(38 \%)$ \\
\hline Sulfonylureas (A10BB) & 18,586 & $554(10 \%)$ & $1558(12 \%)$ & 0.000 & $2112(11 \%)$ \\
\hline Tiazolidininediones (A10BG) & 18,586 & $12(\%)$ & $67(1 \%)$ & 0.001 & $79(\%)$ \\
\hline
\end{tabular}


Table 2 continued

\begin{tabular}{|c|c|c|c|c|c|}
\hline Patient characteristics at baseline & $N^{a}$ & $\begin{array}{l}\text { T2D-CVD } \\
\text { cohort }\end{array}$ & $\begin{array}{l}\text { T2D-others } \\
\text { cohort }^{b}\end{array}$ & $p$ & $\begin{array}{l}\text { All T2D } \\
\text { patients }\end{array}$ \\
\hline Dipeptidyl peptidase- 4 inhibitors $(\mathrm{A} 10 \mathrm{BH})$ & 18,586 & $68(1 \%)$ & $221(2 \%)$ & 0.016 & $289(2 \%)$ \\
\hline $\begin{array}{l}\text { Glucagon-like peptide-1 receptor analogues } \\
\text { (A10BJ) }\end{array}$ & 18,586 & $34(1 \%)$ & $152(1 \%)$ & 0.000 & $186(1 \%)$ \\
\hline $\begin{array}{l}\text { Sodium glucose co-transporter } 2 \text { inhibitors } \\
\text { (A10BK) }\end{array}$ & 18,586 & 0 & 0 & & 0 \\
\hline $\begin{array}{l}\text { Antihypertensive treatments }(\mathrm{C} 03, \mathrm{C} 07, \mathrm{C} 08 \text {, } \\
\mathrm{C} 09)\end{array}$ & 18,586 & $4647(85 \%)$ & $8669(66 \%)$ & 0.000 & $13,316(72 \%)$ \\
\hline Lipid lowering treatment $(\mathrm{C} 10)$ & 18,586 & $3206(58 \%)$ & $5869(45 \%)$ & 0.000 & $9075(49 \%)$ \\
\hline \multicolumn{6}{|c|}{$\begin{array}{l}\text { HbAlc Glycated hemoglobin, } L D L \text { low-density lipoprotein, } S D \text { standard deviation } \\
\text { a Number of patients for whom measurement/value/data were available } \\
\text { b Cohort of patients with T2D but without established CVD } \\
\text { c All patients with T2D meeting inclusion/exclusion criteria and enrolled in the study } \\
\text { d Extracted from the National Diabetes Registry (NDR) } \\
\text { e Codes in parenthesis are the Anatomical Therapeutic Chemical Classification System (ATC) codes }\end{array}$} \\
\hline
\end{tabular}

\section{DISCUSSION}

This population-based register study shows that by 1 January 2012 there were 19,731 patients with T2D in the county of Östergötland, which corresponds to a T2D prevalence of $4.5 \%$. Inclusion and exclusion criteria used in the EMPA REG Outcome study [23] were applied to the T2D cohort, leaving 18,586 patients with T2D for enrollment in the study. Of these, about 30\% had established CVD (T2D-CVD cohort), which is consistent with previous reports from a Swedish setting [5]. Patients in the T2D-CVD cohort were on average older and more often men, and had longer diabetes duration and worse kidney function compared to T2D patients without established CVD.

Patients in the T2D-CVD cohort had a higher risk than those in the T2D-others cohort for a new event even though they received up-todate cardiovascular treatment with antihypertensives and lipid-lowering medications relatively more often. At baseline, i.e., during the first 3 months of $2012,66 \%$ of the patients without known CVD were treated with an antihypertensive and $45 \%$ were treated lipidlowering treatment; corresponding percentages for patients in the T2D-CVD cohort were 85 and $58 \%$, indicating that there is room for improvement. Recommendation values for GLD treatment were the same for T2D patients with and without CVD in terms of HbA1c (52 $\mathrm{mmol} / \mathrm{mol})$ and blood pressure (140/85 $\mathrm{mmHg}$ ). For LDL-cholesterol the values differed between cohorts, with T2D patients with CVD having a lower value $(1.8 \mathrm{mmol} / \mathrm{l})$ than those without CVD $(2.5 \mathrm{mmol} / \mathrm{l})$.

Patients in the T2D-CVD cohort had lower blood pressure and lower cumulative LDL-cholesterol, but their HbA1c was higher and they showed worse signs of kidney injury. This opens the door to new treatments, such as an SGLT 2-inhibitor or GLP 1-analog, which can protect the heart and kidneys $[13,14]$ and thus lower the disease burden and early increased mortality for this patient group, at a reasonable cost.

Our retrospective observation of data on healthcare consumption showed that patients in the T2D-CVD cohort made significantly more 
Table 3 Healthcare visits by patients in the two cohorts during the 5-year follow-up

\begin{tabular}{|c|c|c|c|}
\hline Reason for visit & T2D-CVD cohort & T2D-others cohort & $p$ \\
\hline \multicolumn{4}{|c|}{ Inpatient care (hospitalizations) } \\
\hline Cardiovascular disease & $1.08(1.74)$ & $0.37(0.99)$ & 0.000 \\
\hline Microvascular disease & $0.03(0.22)$ & $0.01(0.14)$ & 0.000 \\
\hline Diabetes & $0.33(0.70)$ & $0.20(0.55)$ & 0.000 \\
\hline Kidney disease & $0.05(0.29)$ & $0.02(0.24)$ & 0.000 \\
\hline Lower limb amputation & $0.02(0.17)$ & $0.00(0.07)$ & 0.000 \\
\hline Other & $1.02(1.69)$ & $0.57(1.25)$ & 0.000 \\
\hline Total Inpatient care & $2.54(3.41)$ & $.18(2.23)$ & 0.000 \\
\hline \multicolumn{4}{|l|}{ Outpatient care (visits) } \\
\hline Cardiovascular disease & $2.53(7.41)$ & $1.00(4.53)$ & 0.000 \\
\hline Microvascular disease & $1.44(9.85)$ & $1.05(4.21)$ & 0.005 \\
\hline Diabetes & $1.01(5.53)$ & $0.80(3.10)$ & 0.009 \\
\hline Kidney disease & $1.89(30.39)$ & $0.53(13.58)$ & 0.002 \\
\hline Lower limb amputation & $0.00(0.08)$ & $0.00(0.05)$ & 0.117 \\
\hline Other & $0.99(2.16)$ & $0.60(1.66)$ & 0.000 \\
\hline Total outpatient care & $7.79(38.52)$ & $3.98(16.98)$ & 0.000 \\
\hline \multicolumn{4}{|l|}{ Primary care (visits) } \\
\hline Cardiovascular disease & $7.55(13.44)$ & $4.40(7.74)$ & 0.000 \\
\hline Microvascular disease & $0.11(0.96)$ & $0.08(0.48)$ & 0.005 \\
\hline Diabetes & $3.81(9.41)$ & $3.42(5.32)$ & 0.003 \\
\hline Kidney disease & $0.18(2.44)$ & $0.07(0.75)$ & 0.001 \\
\hline Lower limb amputation & $0.00(0.07)$ & $0.00(0.03)$ & 0.321 \\
\hline Other & $3.88(6.41)$ & $3.14(3.87)$ & 0.000 \\
\hline Total primary care & $15.49(22.45)$ & $1.08(12.42)$ & 0.000 \\
\hline
\end{tabular}

Data are presented as the average number of visits with the $\mathrm{SD}$ in parenthesis

inpatient visits and had significantly higher costs for inpatient, outpatient, and primary care during the 5-year follow-up than patients in the T2D cohort without established CVD. They also had higher costs for medications and were to a greater extent treated with insulin. Similar to the results of this study, previous research has found that CVD in patients with T2D contributes significantly to treatment costs
[2, 9, 11]. Htay et al. [10] pointed out that although mortality and prevalence of CVD among diabetics have decreased in recent years, they are still twofold higher than in nondiabetics.

In addition to patients in the T2D-CVD cohort having higher healthcare costs, they also had a significantly higher mortality rate compared to patients in the T2D-others cohort over 
Table 4 Healthcare costs (SEK) for the average patient during the 5-year follow-up, distributed over different diseases and types of healthcare services, including drug costs

\begin{tabular}{|c|c|c|c|}
\hline Healthcare costs & T2D-CVD cohort & T2D-others cohort & $p$ \\
\hline \multicolumn{4}{|l|}{ Inpatient care } \\
\hline Cardiovascular disease & $60,434(133,074)$ & $21,737(77,557)$ & 0.000 \\
\hline Microvascular disease & $2653(37,058)$ & $777(12,165)$ & 0.000 \\
\hline Diabetes & $15,771\left(\begin{array}{ll}57 & 193\end{array}\right)$ & $11,649(170,955)$ & 0.014 \\
\hline Kidney disease & 2419 (16 599) & $1222(16,438)$ & 0.000 \\
\hline Lower limb amputation & $1710(18380)$ & $440(10,550)$ & 0.000 \\
\hline Other & $55,483(125,956)$ & $34,220(151,130)$ & 0.000 \\
\hline Total inpatient care & $138,469(235,983)$ & $70,046(255,618)$ & 0.000 \\
\hline \multicolumn{4}{|l|}{ Outpatient care } \\
\hline Cardiovascular disease & $8565(21,513)$ & $3431(12,190)$ & 0.000 \\
\hline Microvascular disease & $2378(30,017)$ & $1444(10,304)$ & 0.024 \\
\hline Diabetes & $2007(12,769)$ & $1358(6448)$ & 0.000 \\
\hline Kidney disease & $5558(85,443)$ & $1701(39,956)$ & 0.001 \\
\hline Lower limb amputation & $32(746)$ & $13(464)$ & 0.075 \\
\hline Other & $3288(8231)$ & $2178(8025)$ & 0.000 \\
\hline Total outpatient care & $21,828(110,533)$ & $10,125(50,083)$ & .000 \\
\hline \multicolumn{4}{|l|}{ Primary care } \\
\hline Cardiovascular disease & $7509(13,827)$ & $4280(8157)$ & 0.000 \\
\hline Microvascular disease & $83(809)$ & $52(399)$ & 0.007 \\
\hline Diabetes & $3449(6502)$ & $3193(4146)$ & 0.007 \\
\hline Kidney disease & $167(936)$ & $75(766)$ & 0.000 \\
\hline Lower limb amputation & $3(115)$ & $0(25)$ & 0.125 \\
\hline Other & $4367(5197)$ & $3585(4825)$ & 0.000 \\
\hline Total primary care & $15,578(18,633)$ & $11,185(12,556)$ & .000 \\
\hline Total healthcare & $175,875(282,044)$ & $91,356(270,597)$ & 0.000 \\
\hline \multicolumn{4}{|l|}{ Medications } \\
\hline Insulin & $9341(15,806)$ & $8029(15,294)$ & 0.000 \\
\hline Consumables $^{\mathrm{a}}$ & $2459(4131)$ & $2383(4400)$ & 0.274 \\
\hline Other diabetes drugs & $2567(7134)$ & 4139 (9501) & 0.000 \\
\hline Cardiovascular-related drugs & $7229(8320)$ & $4337(13,002)$ & 0.000 \\
\hline Other drugs & $24,945(64,204)$ & $22,213(72,118)$ & 0.015 \\
\hline
\end{tabular}


Table 4 continued

\begin{tabular}{llll}
\hline Healthcare costs & T2D-CVD cohort & T2D-others cohort & $\boldsymbol{p}$ \\
\hline Total medications & $46,541(70,915)$ & $1,100(78,377)$ & 0.000 \\
Total costs & $222,416(304,637)$ & $132,456(290,003)$ & 0.000 \\
\hline
\end{tabular}

Data are presented as the average (in SEK) with the SD in parenthesis

${ }^{a}$ For example: blood sugar test strips and lancets

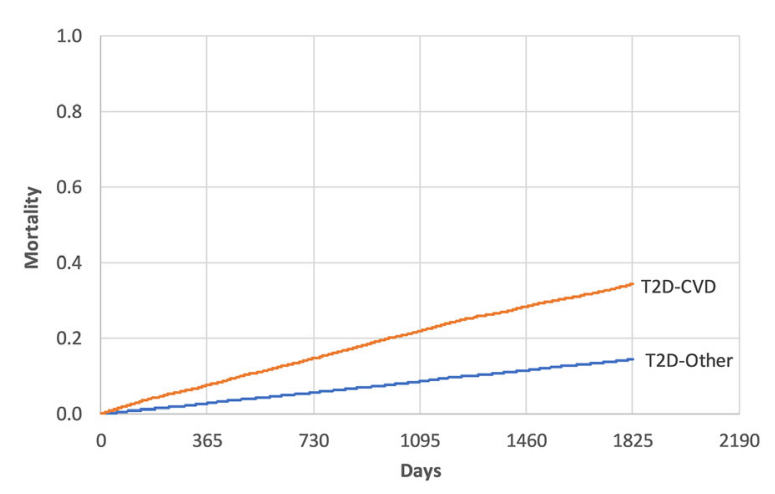

Fig. 2 Cumulative mortality for the T2D-CVD and T2D-others cohort

5 years of follow-up (34 vs. 15\%). This difference in mortality can be translated into the patients with established CVD having approximately 200 fewer days of life than those without established CVD over the 5 years of follow-up.

CVD is common among T2D patients, and it is obvious from our study that established CVD constitutes a major burden to this patient population, with a negative impact on survival and higher healthcare costs. These findings are important as they contribute to a better understanding of the situation of this exposed group of patients. The relatively long follow-up of this study gives a fuller picture than that reported in previous studies with shorter time horizons.

The results of this study confirm that CVD is a major aggravating factor for T2D patients. This knowledge has contributed to the development of new GLDs in recent years that combine a glucose-lowering effect with a protective effect against CV events. Treatment of patients with T2D and established CVD with either SGLT-2-inhibitors or GLP-1 receptor agonists is recommended in both an international setting (by ESC and ADA/EASD) and by the Swedish National Board of Health and Welfare. Our results clearly point to the need to optimize the treatment of patients with T2D and established CVD, ensuring that medications with shown mortality gains are considered in line with national and international guidelines.

The major challenges facing clinicians when it comes to offering newer, efficacious medications without unnecessary delay to the patients who will benefit the most are the increasing prevalence of diabetes overall and the relatively poor adherence of patients to guidelines.

\section{Strengths and Limitations}

A strength of this study is that all T2D patients in Östergötland, with and without established CVD, were included in the analysis. Further, high-quality registers were used to follow all patients for up to 5 years (2012-2016). The good coverage of the registers used gives reliable results.

However, some caution should be exercised regarding the generalizability of these results. While Östergötland is usually considered to be representative of the whole of Sweden, the results cannot be directly applied to other countries, especially outside the Western world. Also, our results are from the time period 2012-2016 and thus reflect the reality of a few years back. We used this time period because SGLT-2 inhibitors were not introduced into use in Östergötland until 2017 and we wanted to study the reality of patients with T2D and established CVD without access to SGLT-2 inhibitors. 


\section{CONCLUSION}

In conclusion, the results of this study confirm that established CVD is common among patients with T2D, with a prevalence of about $30 \%$. Established CVD in patients with T2D is associated with higher morbidity, mortality, and healthcare costs compared to T2D patients without established CVD.

\section{ACKNOWLEDGEMENTS}

Funding. This study was sponsored by a grant from Boehringer Ingelheim, Sweden. The journal's Rapid Service Fee was funded by the Linköping University library.

Authorship. All named authors meet the International Committee of Medical Journal Editors (ICMJE) criteria for authorship for this article, take responsibility for the integrity of the work as a whole, and have given their approval for this version to be published.

Disclosures. Lars Bernfort, Magnus Husberg, Ann-Britt Wiréhn, Ulf Rosenqvist and Lars-Åke Levin have nothing to disclose. Staffan Gustavsson and Kristina Karlsdotter are employed by Boehringer Ingelheim.

Compliance with Ethics Guidelines. The study was approved by the Regional Ethics Research Committee in Östergötland, Sweden (Dnr: 2017/535-31). The study was performed in accordance with the Helsinki Declaration of 1964, and its later amendments.

Data Availability. The datasets generated during and/or analyzed during the current study are available from the corresponding author on reasonable request.

Open Access. This article is licensed under a Creative Commons Attribution-NonCommercial 4.0 International License, which permits any non-commercial use, sharing, adaptation, distribution and reproduction in any medium or format, as long as you give appropriate credit to the original author(s) and the source, provide a link to the Creative Commons licence, and indicate if changes were made. The images or other third party material in this article are included in the article's Creative Commons licence, unless indicated otherwise in a credit line to the material. If material is not included in the article's Creative Commons licence and your intended use is not permitted by statutory regulation or exceeds the permitted use, you will need to obtain permission directly from the copyright holder. To view a copy of this licence, visit http://creativecommons.org/licenses/by$\mathrm{nc} / 4.0 /$.

\section{REFERENCES}

1. Cannon A, Handelsman Y, Heile M, Shannon M. Burden of illness in type 2 diabetes mellitus. J Manag Care Spec Pharm. 2018;24(9):S5-S13.

2. Ramzan S, Timmins P, Hasan SS, Babar ZUD. Cost analysis of type 2 diabetes mellitus treatment in economically developed countries. Expert Rev Pharmacoecon Outcomes Res. 2019;19(1):5-14.

3. Huebschmann AG, Huxley RR, Kohrt WM, Zeitler P, Regensteiner JG, Reusch JEB. Sex differences in the burden of type 2 diabetes and cardiovascular risk across the life course. Diabetologia. 2019;62(10): 1761-72.

4. Swedish National Board of Health and Welfare. National guidelines for diabetes care-support for governance and management. Stockholm:Swedish National Board of Health and Welfare; 2018.

5. Eliasson B, Ekelund J, Amberntsson R, Miftaraj M, Svensson AM. Cardiovascular disease in patients with type 2 diabetes and in patients starting empagliflozin treatment: nationwide survey. Diabetes Ther. 2019;10(4):1523-30.

6. Rawshani A, Rawshani A, Franzen S, et al. Mortality and cardiovascular disease in type 1 and type 2 diabetes. N Engl J Med. 2017;376(15):1407-18.

7. Rawshani A, Rawshani A, Franzen S, et al. Risk factors, mortality, and cardiovascular outcomes in patients with type 2 diabetes. $\mathrm{N}$ Engl J Med. 2018;379(7):633-44.

8. Weng $\mathrm{W}$, Tian $\mathrm{Y}$, Kong SX, et al. Impact of atherosclerotic cardiovascular disease on healthcare resource utilization and costs in patients with type 
2 diabetes mellitus in a real-world setting. Clin Diabetes Endocrinol. 2020;6:5.

9. Einarson TR, Acs A, Ludwig C, Panton UH. Economic burden of cardiovascular disease in type 2 diabetes: a systematic review. Value Health. 2018;21(7):881-90.

10. Htay T, Soe K, Lopez-Perez A, Doan AH, Romagosa MA, Aung K. Mortality and cardiovascular disease in type 1 and type 2 diabetes. Curr Cardiol Rep. 2019;21(6):45.

11. Rosengren A, Edqvist J, Rawshani A, et al. Excess risk of hospitalisation for heart failure among people with type 2 diabetes. Diabetologia. 2018;61(11): 2300-9.

12. Wirehn AB, Andersson A, Ostgren CJ, Carstensen J. Age-specific direct healthcare costs attributable to diabetes in a Swedish population: a register-based analysis. Diabet Med. 2008;25(6):732-7.

13. Zelniker TA, Wiviott SD, Raz I, et al. SGLT2 inhibitors for primary and secondary prevention of cardiovascular and renal outcomes in type 2 diabetes: a systematic review and meta-analysis of cardiovascular outcome trials. Lancet. 2019;393(10166):31-9.

14. Kristensen SL, Rorth R, Jhund PS, et al. Cardiovascular, mortality, and kidney outcomes with GLP-1 receptor agonists in patients with type 2 diabetes: a systematic review and meta-analysis of cardiovascular outcome trials. Lancet Diabetes Endo. 2019;7(10):776-85.

15. Santamarina M, Carlson CJ. Review of the cardiovascular safety of dipeptidyl peptidase- 4 inhibitors and the clinical relevance of the CAROLINA trial. BMC Cardiovasc Disor. 2019; 19:60.https://doi.org/ 10.1186/s12872-019-1036-0.

16. Cosentino F, Grant PJ, Aboyans V, et al. 2019 ESC Guidelines on diabetes, pre-diabetes, and cardiovascular diseases developed in collaboration with the EASD. Eur Heart J. 2020;41(2):255-32323.
17. Buse JB, Wexler DJ, Tsapas A, et al. 2019 Update to: Management of hyperglycemia in type 2 diabetes, 2018. A consensus report by the American Diabetes Association (ADA) and the European Association for the Study of Diabetes (EASD). Diabetes Care. 2020;43(2):487-93.

18. Henriksson F, Jonsson B. Diabetes: the cost of illness in Sweden. J Intern Med. 1998;244(6):461-8.

19. Henriksson F, Agardh CD, Berne C, et al. Direct medical costs for patients with type 2 diabetes in Sweden. J Intern Med. 2000;248(5):387-96.

20. Bexelius C, Lundberg J, Wang X, Berg J, Hjelm H. Annual medical costs of Swedish patients with type 2 diabetes before and after insulin initiation. Diabetes Ther. 2013;4(2):363-74.

21. Ringborg A, Martinell M, Stalhammar J, Yin DD, Lindgren P. Resource use and costs of type 2 diabetes in Sweden-estimates from population-based register data. Int J Clin Pract. 2008;62(5):708-16.

22. Sabale U, Bodegard J, Sundstrom J, et al. Healthcare utilization and costs following newly diagnosed type-2 diabetes in Sweden: A follow-up of 38,956 patients in a clinical practice setting. Prim Care Diabetes. 2015;9(5):330-7.

23. Zinman B, Wanner C, Lachin JM, et al. Empagliflozin, cardiovascular outcomes, and mortality in type 2 diabetes. N Engl J Med. 2015;373(22): 2117-288.

24. Swedish National Board of Health and Welfare. National Prescribed Drugs Register. https://www. socialstyrelsen.se/statistik-och-data/register/allaregister/lakemedelsregistret/. 2019. Accessed Jan 2019.

25. Swedish National Board of Health and Welfare. Cause of Death Register. https://www. socialstyrelsen.se/statistik-och-data/register/allaregister/dodsorsaksregistret/. 2019. Accessed Jan 2019.

26. National Diabetes Register. Annual report. https:// www.ndr.nu// 2019. Accessed Jan 2019. 